Linha D'Água (Online), São Paulo, v. 29, n. 1, p. 29-43, jun. 2016

\title{
POR UMA MEMÓRIA DA ÁFRICA E DOS AFRODESCENDENTES: ASPECTOS TEÓRICOS E LEGAIS PARA O ENSINO DE LITERATURAS AFRICANAS E AFRO-BRASILEIRA
}

\author{
FOR A MEMORY OF AFRICA AND AFRO-DESCENDENTS: \\ THEORETICAL AND LEGAL ASPECTS FOR THE TEACHING OF \\ AFRICAN AND AFRO-BRAZILIAN LITERATURES
}

\author{
Vima Lia de Rossi Martin* \\ Universidade de São Paulo, São Paulo, SP, Brasil \\ André de Godoy Bueno** \\ EMEF Antonio Carlos de Andrada e Silva, São Paulo, SP, Brasil
}

\begin{abstract}
Resumo: 0 presente artigo focaliza aspectos teóricos e legais que embasam a abordagem das literaturas afficanas e afro-brasileira na educação brasileira. Tal intenção articula-se à Lei 10.639/2003, cujo escopo é 0 ensino de história e cultura africana e afro-brasileira em todos os niveis educacionais no Brasil. A referida Lei deve nortear as propostas educacionais desde o nível básico até 0 ensino superior, sendo contemplada na formulacão dos projetos pedagógicos das escolas e nas próprias aulas. Assim, discute-se uma abordagem pedagógica ligada ao ensino de literatura, num sentido amplo, e, em pormenor, a 0 ensino das literaturas africanas e afro-brasileira. 0 objetivo do estudo é contribuir para a consolidação da educacạ̃o para as relações étmico-raciais, bem como ressaltar a importância de ações legais para a sua efetivaç̦̃o.
\end{abstract}

Palavras-chave: Literatura e educação; Literaturas africanas; Literatura afro-brasileira; Lei 10.639/03; Memória.

Abstract: This article focuses on theoretical and legal aspects that underpin the approach of African and afro-Brazilian literatures in Brazilian education. Such intention is articulated to the Law $10.639 / 2003$, whose purpose is the teaching of African and afro-Brazilian history and culture at all educational levels in Brazil. This law should guide the educational proposals from basic to higher education, being contemplated in the formulation of educational projects of the schools and in their classes. Thus, we discuss a pedagogical approach linked to the teaching of literature, in a broad sense, and, in detail, the teaching of African and afro-Brazilian literatures. The objective of this study is to contribute for the consolidation of education for ethnic-racial relationships, underscoring the importance of legal measures for their realization.

Keywords: Literature and Education; African Literatures; Afro-Brazilian Literature; Law 10.639/03; Memory.

* Professora da Universidade de São Paulo - USP, São Paulo, Brasil; vima@usp.br
* * Professor da EMEF Antonio Carlos de Andrada e Silva, São Paulo, Brasil; andre_paff@hotmail.com 
Linha D'Água (Online), São Paulo, v. 29, n. 1, p. 29-43, jun. 2016

\section{Introdução}

As reflexões sobre o ensino de literatura, no Brasil, vêm ganhando cada vez mais espaço ao longo dos últimos anos ${ }^{1}$. Os debates acerca do ensino de português foram amplamente influenciados pelos Parâmetros Curriculares Nacionais, publicados em 1996, cuja concepção optou por um enfoque mais direcionado à variedade de gêneros textuais, impactando, assim, o trabalho docente também no campo literário. Desse modo, é fato que houve uma certa instrumentalização do ensino da literatura, que em algumas situações de abordagem presentes em estudos acadêmicos e manuais didáticos, por exemplo, é esvaziada de suas especificidades enquanto elaboração artística.

Entretanto, os estudos sobre a literatura, como campo específico do saber e enquanto disciplina escolar, fazem parte da preocupação de teóricos como Antonio Candido (2013), Nelly Novaes Coelho (2000), Regina Zilberman (2008), entre outros. Tais autores apresentam concepções de literatura e de ensino e aprendizagem fundamentais, que se mostram afinadas com a realidade social brasileira e as demandas de nossa educação, com suas inúmeras particularidades.

$\mathrm{Na}$ esteira da reflexão promovida por esses autores, propõe-se aqui uma discussão inicial focada no ensino da leitura e da literatura na escolarização básica. $\mathrm{Na}$ sequência, estende-se a reflexão para o campo das literaturas africanas e afro -brasileira, cuja circulação na escola deve ser vista como direito de aprendizagem e possibilidade formativa do leitor literário e do cidadão crítico, e não somente como obrigação legal.

As considerações finais tratam de explicitar que já são encontrados avanços em relação à abordagem dessas literaturas em nosso sistema educacional. Contudo, torna-se essencial salientar que em nosso país as relações étnicas são complexas e muitas vezes ambíguas, fator que implica a exclusão racial não apenas na realidade escolar que conhecemos, mas em toda a sociedade.

\section{0 ensino de literatura na escola}

A atividade docente diferencia-se no âmbito profissional pelo caráter formativo de sua ação. A escola não pode ser apenas um espaço de transmissão de conteúdos científicos. Tal concepção, apesar de presente ainda no imaginário de parte da população e dos/as professores/as, tem sido superada por formas mais contemporâneas de se considerar o ensino. Freire já insistia, em relação a educadores/as, que

Este artigo tem origem na pesquisa desenvolvida no âmbito do Mestrado Profissional em Letras (PROFLETRAS), na Universidade de São Paulo, entre 2014 e 2015. 
Linha D'Água (Online), São Paulo, v. 29, n. 1, p. 29-43, jun. 2016

"faz parte de sua tarefa docente não apenas ensinar os conteúdos, mas também ensinar a pensar certo" (FREIRE, 2014, p. 28).

Essa visão, para o pedagogo, vincula-se à prática e à reflexão sobre essa prática, para que o ensino não seja mecanicista e desarticulado de seu objetivo formativo. Segundo o autor, cada docente deve "Saber que ensinar não é transferir conhecimento, mas criar as possibilidades para a sua produção ou a sua construção" (FREIRE, op. cit., p. 47).

O educador defende uma concepção abrangente acerca da leitura, entendendo-a sobretudo como leitura do mundo. É importante que os professores considerem esse fator porque, se a escola é responsável pela formação de leitores de textos e do mundo, é preciso rever a imposição da leitura obrigatória e burocrática, circunstância que mais afasta do que aproxima os estudantes dos livros.

Não há dúvidas de que o condicionamento da leitura pode influenciar a sua eficácia. Some-se a isso a dificuldade que docentes encontram para efetivar o seu trabalho, com situações adversas de alfabetização e diante do variado arcabouço cultural que cada aluno traz para a escola, principalmente no que se refere às redes públicas de educação. A esse respeito, Regina Zilberman afirma que:

Da alfabetização, tarefa que a escola desempenhou burocraticamente desde seus inícios, passou-se à necessidade de letramento, sobretudo de letramento literário. A leitura de texto apresenta-se como prática inusitada, e a literatura, em boa parte das escolas nacionais, como um alienígena, sobretudo nas que atendem os segmentos populares, mesmo em grandes centros urbanos (ZILBERMAN, 2008, p. 15).

Essa situação coloca ao corpo docente grandes desafios. Deslocou-se o foco da alfabetização para o letramento - e, mais recentemente, para o letramento literário. Mas as discussões sobre as especificidades dos processos de leitura literária, ou seja, de apropriação da literatura e de atribuição de sentidos ao texto literário, nem sempre estão ao alcance dos/as professores/as da educação básica.

Se, no âmbito do ensino de língua portuguesa, tiveram papel de destaque os estudos linguísticos que, por meio de pesquisadores como João Wanderley Geraldi (1997), por exemplo, impactaram positivamente novas concepções de abordagem linguística, o mesmo parece não ter acontecido em relação aos estudos literários. Ao contrário, a ênfase na leitura e produção textual de variados gêneros, com o estudo sistemático de textos cotidianos, como notícias, histórias em quadrinhos, receitas culinárias etc., parece ter relegado a literatura a um plano subalterno. E suas especificidades, em razão de sua natureza artística, frequentemente são negligenciadas. 
Linha D'Água (Online), São Paulo, v. 29, n. 1, p. 29-43, jun. 2016

Nesse contexto, é necessário que haja compreensão do importante papel desempenhado pela literatura na formação do leitor. Não apenas do leitor "técnico", isto é, daquele leitor que compreende as estruturas e propriedades compositivas dos textos literários, mas especialmente do leitor de si mesmo e do mundo - aquele sujeito que, sensibilizado pela literatura, pode, num sentido mais amplo, aprimorar seu desenvolvimento pessoal e desenvolver o senso crítico, ultrapassando a mera decodificação formal e estilística da literatura.

Sem uma abordagem consistente, que dê conta das dimensões objetiva e subjetiva que envolvem a elaboração e a recepção dos textos literários, professores/as de português correm o risco de negligenciar o potencial humanizador que uma obra literária pode exercer ao longo da formação pessoal de cada discente. Essa força presente na literatura deve ser explorada, maximizada, a fim de que seus efeitos se tornem visíveis e perenes.

Nem sempre há clareza sobre os motivos pelos quais a educação contempla a leitura do texto literário. Aparentemente, a literatura não tem aplicação prática para o dia a dia discente, o que a tornaria pouco atrativa e desvinculada do horizonte quase sempre utilitário da escola. Por isso, é importante o debate sobre as razões que levam a literatura a constar como conteúdo da escolarização. Nelly Novaes Coelho, por exemplo, considera a escola como um espaço privilegiado para que se dê o encontro entre o leitor e o livro. A pesquisadora afirma:

\begin{abstract}
Nossa linha de trabalho assenta no princípio de que a escola é, hoje, o espaço privilegiado, em que deverão ser lançadas as bases para a formação do indivíduo. E, nesse espaço, privilegiamos os estudos literários, pois, de maneira mais abrangente que quaisquer outros, eles estimulam o exercício da mente; a percepção do real em suas múltiplas significações; a consciência do eu em relação ao outro; a leitura do mundo em seus vários níveis e, principalmente, dinamizam o estudo e conhecimento da língua, da expressão verbal significativa e consciente - condição sine qua non para a plena realidade do ser (COELHO, 2000, p. 16).
\end{abstract}

A especialista elenca uma série de motivos que tornam o texto literário um veículo poderoso na formação dos estudantes. Essa visão se funda na experiência de Coelho com a literatura em vários níveis, da educação básica à superior.

Já Antonio Candido, em "O direito à literatura" (2013), defende a relevância do texto literário para a vida dos sujeitos. Candido admite, com base na reflexão de Louis-Joseph Lebret, a existência de bens compressíveis e incompressíveis para a humanidade, afirmando que "Certos bens são obviamente incompressíveis, como o alimento, a casa, a roupa. Outros são compressíveis, como os cosméticos, os 
Linha D'Água (Online), São Paulo, v. 29, n. 1, p. 29-43, jun. 2016

enfeites, as roupas supérfluas" (CANDIDO, 2013, p. 175). O autor observa que a definição desses bens não é simples de se fixar, porque faz-se necessário delimitar o que seria indispensável à vida. $\mathrm{O}$ estudioso liga a questão aos direitos humanos, afirmando que:

Por isso, a luta pelos direitos humanos pressupõe a consideração de tais problemas e chegando mais perto do tema [os direitos humanos] eu lembraria que são bens incompressíveis não apenas os que asseguram a sobrevivência física em níveis decentes, mas os que garantem a integridade espiritual. São incompressíveis certamente a alimentação, a moradia, o vestuário, a instrução, a saúde, a liberdade individual, o amparo da justiça pública, a resistência à opressão etc.; e também o direito à crença, à opinião, ao lazer e, por que não, à arte e à literatura. (CANDIDO, 2013, p. 176)

$\mathrm{O}$ argumento do autor se baseia na noção abrangente do que considera literatura. Para ele, podem ser considerados como textos literários "todas as criações de toque poético, ficcional ou dramático em todos os níveis de uma sociedade, em todos os tipos de cultura", sendo a literatura a "manifestação universal de todos os homens em todos os tempos" (idem). Por isso, Candido pressupõe que todos os seres humanos necessitam de literatura, não havendo quem consiga viver sem entrar em contato com alguma espécie de fabulação. Desse modo, a literatura é vista pelo autor como um bem incompressível ao ser humano, ao qual todos devem ter acesso, fazendo parte de necessidades elementares. Ele ainda afirma:

Negar a fruição da literatura é mutilar a nossa humanidade. [...] a literatura pode ser um instrumento consciente de desmascaramento, pelo fato de focalizar as situações de restrições dos direitos, ou de negação deles, como a miséria, a servidão, a mutilação espiritual. Tanto num nível quanto no outro ela tem muito a ver com a luta pelos direitos humanos (CANDIDO, 2013, p. 188).

Se, como quer o teórico, a nossa humanidade seria mutilada sem a literatura, ela deixa de constituir simplesmente mais um componente do currículo escolar. Pelo contrário, sua leitura passa a ser entendida enquanto direito discente e possibilidade formativa dentro das aulas de português. É certo que não é somente na escola que há acesso à literatura, mas é igualmente verdadeiro que muitas pessoas não experimentaram, em suas vidas anteriores à escolarização, a leitura literária, principalmente quando se consideram pessoas de classes sociais menos abastadas. 
Caberia à escola, nesses casos, a iniciação de tais pessoas à leitura, em geral, e à leitura literária, em especial. Nesse sentido, e como já apontamos, preocupa-nos o fato de que a literatura está perdendo espaço nas práticas didáticas de português. Se a linguística aplicada ao ensino avançou nas últimas décadas e ganhou terreno na escola, a literatura, em contrapartida, perdeu parte de seu prestígio.

O problema, aqui, vale esclarecer, não é o advento de uma perspectiva renovada em relação ao ensino da língua - que é muito bem-vinda -, mas é justamente a subordinação da leitura do texto literário a uma lógica instrumental, atrelada ao ensino e à aprendizagem dos gêneros textuais. Se a leitura dos textos literários se ativer prioritariamente ao desenvolvimento das habilidades linguísticas dos alunos, ela pode ser esvaziada de seu potencial transformador, tornando-se um mero objeto para o ensino de estruturas gramaticais. Perde-se, então, os objetivos mais abrangentes de formação pessoal - ética e psicológica - do sujeito aprendiz.

O direito do aluno de aprender, tão bem defendido por Freire, e o direito à literatura, tal como o propõe Candido, parecem-nos excelentes balizas para orientar o trabalho do professor de português com a literatura. São visões que podem gerar práticas mais adequadas à escola contemporânea, ampliando suas possibilidades de intervenção na formação de alunos mais plenos e portadores de consciência crítica.

\section{Literaturas africanas e afro-brasileira em perspectiva}

Que literatura ensinar na escola? Essa questão, central para orientar o trabalho de professores de português, ganha importância no cenário contemporâneo, em que emergem demandas pelo ensino não apenas de novos conteúdos, relacionados aos desafios próprios da realidade atual, mas sobretudo pela relativização da perspectiva eurocêntrica, tradicional na estruturação dos currículos brasileiros.

No campo do ensino de literatura, parece-nos fundamental a ampliação dos conteúdos já canônicos, relativos às literaturas de língua portuguesa. Segundo entendemos, a leitura de poemas e narrativas brasileiras e portuguesas deve vir acompanhada da leitura de outros textos não canônicos, essenciais para a compreensão de aspectos referentes a nossa formação social e cultural: se a literatura deve ser um direito dos estudantes, é indispensável que as literaturas africanas e afro-brasileira constituam esse direito. Cumpre reiterar que a Lei $10.639 / 03^{2}$ prevê que alunos, de todos os níveis de ensino no Brasil, estudem história e cultura africana

2 A Lei 11.645/08 altera a Lei 10.639/03 e prevê também a inclusão da história e cultura indígenas no currículo oficial. Todavia, trataremos aqui exclusivamente da questão étnico-racial vinculada aos negros, sem desconsiderar a importância do ensino de temas indígenas. 
Linha D'Água (Online), São Paulo, v. 29, n. 1, p. 29-43, jun. 2016

e afro-brasileira. Nessa obrigação, incluem-se as suas respectivas literaturas, posto que compõem parte significativa do acervo cultural e histórico de países que estão na origem de nossa constituição enquanto brasileiros.

É importante atentar, porém, para o fato de que a inclusão dos temas de história e cultura africana e afro-brasileira é bastante abrangente e deve ser realizada com o devido cuidado. Não é desejável que a inserção dessas temáticas seja apenas mais um objeto de estudo para simplesmente constar do currículo oficial. É necessário destacar quais são as reais intenções do trabalho exigido por essa Lei; afinal, implicada nessa obrigação está a valorização cultural das origens étnicas de nossa nação.

A questão proposta na seção anterior pode ser, então, desdobrada: se é necessário que haja clareza acerca das razões que motivam o ensino de literatura na escola, faz-se igualmente importante refletir sobre os motivos que levam a escola a considerar como parte de seus objetivos o estudo das literaturas africanas e afro-brasileira.

Inicialmente, a consideração de que há uma Lei que impõe essa obrigatoriedade já é uma razão para que professores/as incluam em suas aulas e em seus projetos pedagógicos tais literaturas. É evidente, no entanto, que as motivações, quando bem fundamentadas, tendem a ampliar a sua eficácia. Portanto, se docentes de língua portuguesa estiverem conscientes da importância de seu trabalho com relação às literaturas africanas e afro-brasileira, tanto mais farão para que a sua valorização seja um fato cotidiano na escola, e não o mero cumprimento legal.

Embora haja um processo lento e gradual de assimilação do conhecimento necessário para a apropriação e efetivação da Lei 10.639/03, é possível perceber que, progressivamente, algumas ações significativas vêm sendo desenvolvidas, como atestam diversas publicações sobre o tema, como o livro Educação como prática da diferença (2006), por exemplo. A demanda que essa Lei engendra não se restringe ao ensino de alguns elementos relacionados à África ou aos afrodescendentes. Mais do que incluir conteúdos nos currículos, há a exigência de uma readequação do sistema escolar brasileiro para a sua efetivação. É importante uma reflexão sobre quais conteúdos e sobretudo quais atitudes devem permear o ensino, haja vista que a Lei visa a reequilibrar as relações étnico-raciais no Brasil. Acerca disso, Rocha aponta que:

A educação, vista pelo viés da diversidade cultural, torna-se um desafio na atualidade brasileira. Pois ela será obrigada a fazer o exercício de rever os seus caminhos refletindo como ensina, e o que ensina. Principalmente no que diz respeito às africanidades e às vivências dos estudantes relacionadas ao racismo (ROCHA, 2011, p. 31). 
De acordo com a pesquisadora, não só o que é ensinado deve receber atenção, mas também o modo como se ensina. Nesse sentido, surge a necessidade de uma reflexão mais apurada não apenas sobre o que será trabalhado cotidianamente, mas principalmente sobre quais serão os enfoques adotados, como cada escola conduzirá a temática etc.

Para auxiliar os profissionais da educação, foram instituídas as Diretrizes Curriculares Nacionais para a Educação das Relaçôes Étnico-Raciais e para o Ensino de História e Cultura Afro-Brasileira e Africana (2004) e as Orientações e Ações para a Educação das Relaçôes Étnico-raciais (2006), que contemplam as especificidades que não são próprias à objetividade da Lei. Tais documentos, disponíveis no portal do MEC, fazem uma abordagem das relações étnico-raciais no âmbito educacional, traçando caminhos que são importantes para a questão, dialogando com as políticas reparatórias/afirmativas, com temas históricos relacionados a aspectos da diversidade étnica, entre outros.

Ao discutir a relação entre escola e racismo, por exemplo, o texto das Orientaçôes e Ações para a Educação das Relaçôes Étnico-raciais esclarece como o silenciamento pode ser uma arma poderosa na manutenção das hierarquias raciais, favorecendo a consolidação de pensamentos e práticas avessas ao exercício da convivência com a diferença:

O silêncio da escola sobre as dinâmicas das relações raciais tem permitido que seja transmitida aos(as) alunos(as) uma pretensa superioridade branca, sem que haja questionamento desse problema dos(as) profissionais da educação e envolvendo o cotidiano escolar em práticas prejudiciais ao grupo negro. Silenciar-se diante do problema não apaga magicamente as diferenças, e, ao contrário, permite que cada um construa, a seu modo, um entendimento muitas vezes estereotipado do outro que lhe é diferente. Esse entendimento acaba sendo pautado pelas vivencias sociais de modo acrítico, conformando a divisão e a hierarquização raciais (BRASIL, 2006, p. 23).

Existe uma questão fundamental quando se trata da abordagem dos contextos africanos no ensino brasileiro, que pode ser formulada através da seguinte maneira: de que valores, de que culturas devemos tratar? Para se ter uma ideia da enorme diversidade em pauta, basta observar que a África é um continente composto atualmente por mais de cinquenta países independentes. É também o segundo continente mais populoso do planeta, com mais de um bilhão de habitantes, ficando atrás apenas da Ásia. Assim, sua produção cultural é vasta e muitíssimo diversa. Por isso, o/a professor/a precisa ter algum domínio sobre o repertório escolhido 
Linha D'Água (Online), São Paulo, v. 29, n. 1, p. 29-43, jun. 2016

para leitura e, sobretudo, precisa ter clareza de seus objetivos ao inserir a temática histórica e cultural africana e afro-brasileira no seu rol de ações educativas.

Uma postura fundamental consiste em admitir que a participação das culturas africanas na formação da cultura brasileira é central, reconhecendo como imprópria a vinculação da população africana que aqui viveu e de seus descendentes apenas à vergonhosa página da escravidão, como outrora ocorria numa educação de base eurocêntrica.

Como se sabe, durante séculos o poder institucional em nosso país desvalorizou e invisibilizou diferentes aspectos sociais e culturais que se relacionam às populações africanas. Isso se deveu principalmente ao fato de que as pessoas trazidas para o Brasil na condição de escravas foram sistematicamente exploradas e oprimidas e tiveram suas tradições, religiões e valores considerados de menor relevância, ou até mesmo aniquilados. Para os negros brasileiros, a desvalorização da aparência física, bem como de suas ações e atividades, é uma realidade que perdura até hoje.

Nesse contexto, as literaturas africanas e a produção literária afro-brasileira, como elaborações culturais relevantes, quase nunca fizeram parte dos conteúdos de ensino da escola básica. E, especialmente em relação à literatura brasileira produzida por afrodescendentes, sua abordagem, quando ocorre, não enfatiza a origem étnica dos autores. Também as universidades, de modo geral, deram pouca importância ao fato de que diversos escritores brasileiros possuem ascendência africana, oferecendo somente o enfoque da qualidade de suas produções, mesmo tendo como expoentes nomes da envergadura de Machado de Assis, Lima Barreto, Cruz e Souza, Solano Trindade etc. E há situações ainda mais cruéis, como se observa em relação a figuras como Maria Firmina dos Reis (1825-1917), romancista negra e maranhense, cuja obra só mais recentemente tem recebido o devido reconhecimento.

Aliás, vale aqui comentar alguns aspectos da biografia e da obra de Lima Barreto (1881-1922), que nos parecem ilustrar de modo exemplar os limites e as contradições atinentes à trajetória dos intelectuais afro-brasileiros. Tal drama se acentua se tivermos em conta o momento histórico vivido pelo escritor, marcado pelo Positivismo e por ideologias de cunho racista. Negro, alcoolista, funcionário público de baixos rendimentos, o autor carioca de fato parece ter sofrido - de maneira sistemática - inúmeros preconceitos. Como se sua própria história de vida constituísse uma denúncia de que as promessas de inclusão social e de avanço democrático embutidas no novo regime republicano, e não cumpridas até o presente, eram falaciosas.

Nesse sentido, a pesquisadora Lilia Moritz Schwarcz, em estudo introdutório aos Contos completos do autor, antologia publicada em 2010, aponta que cor da 
pele foi um entrave ao reconhecimento e à ascensão social de Lima Barreto que, em 1919 tentou, sem sucesso, entrar para a Academia Brasileira de Letras. Nunca é demais lembrar que, num cenário social brasileiro marcado por determinismos, a condição dos negros e mestiços era frequentemente associada à perversão e à degeneração, e a autonomia intelectual era praticamente vetada aos homens de cor. Daí a emergência do drama vivido por:

determinados intelectuais negros (pouquíssimos por sinal) que tentavam combater o racismo científico mas esbarravam no conceito determinista de raça e em suas consequências sempre negativas. Autores como Manuel Querino, José do Patrocínio ou Lima Barreto, raros nesse contexto em que "apagar a cor" era medida cautelosa e necessária, acabaram por viver em permanente dilema, conflito e contradição entre a projetada inclusão e a realidade da exclusão social ( $\mathrm{SCH}-$ WARCZ, 2010, p. 23-24).

Ao identificar que Lima Barreto era portador de uma identidade cindida, a autora do estudo sugere que o autor tenha vivido uma espécie de desterro intelectual e enfatiza os movimentos de aproximação e distanciamento travados por ele com as elites intelectuais de seu tempo, mantendo, quase sempre, uma atitude avessa à ambiência hipócrita dos círculos mais prestigiados.

Os textos em prosa de Lima Barreto, que transitam entre literatura, jornalismo, intervenção social e política, manifestam formalmente sua rebeldia diante dos padrões vigentes - as fórmulas linguísticas rebuscadas e preciosistas tão cultuadas durante a belle époque. $\mathrm{O}$ escritor tinha a consciência de que o refinamento excessivo no uso da língua estava ligado a um modelo artificial e elitista, distanciado do público leitor com o qual pretendia estabelecer uma comunicabilidade direta.

Expressando frequentemente sua visada crítica sobre a realidade nacional através de uma dicção transgressora e de uma ironia de acento melancólico, Lima Barreto parece ter alimentado sua obra com o caráter problemático da sua visão sobre a sociedade e de sua pertinência a ela. Nesse sentido, o escritor faz uma opção clara pelos excluídos, abordando os problemas característicos de sua condição. Seu posicionamento se torna ainda mais audacioso se considerarmos que ele se dá num momento histórico (oficial) de euforia, em que havia empenho para que fossem apagadas as marcas da colonização e da escravidão. Nas palavras de Schwarcz:

O autor constrói, assim, uma literatura que se pretende negra, suburbana e pobre. Numa época em que mais se exaltava a abolição do que se lembrava do passado escravocrata, num contexto em que o próprio Hino da República, feito apenas dois anos após a libertação dos escravos, dizia "nós nem cremos que escravos 
Linha D'Água (Online), São Paulo, v. 29, n. 1, p. 29-43, jun. 2016

outrora tenha havido em tão nobre país", Lima Barreto fazia questão de trazer o tema para o presente (SCHWARCZ, 2010, p. 29).

Note-se que é justamente a pretensão do escritor de fazer uma literatura negra que faculta sua inserção num campo específico, o da chamada literatura afro -brasileira. A constituição desse repertório literário singular, marcado pela afirmação étnico-racial, tem como um de seus principais objetivos a reformulação da tradição literária brasileira, no sentido de torná-la mais plural e representativa. Assim, é na contramão da brancura ideológica e estética que pautou a consolidação de nosso cânone literário que se inscrevem os textos literários em que se observam posicionamentos discursivos contrários à escravidão e às suas perniciosas heranças.

Como esclarece Eduardo de Assis Duarte, no artigo "Notas sobre a literatura brasileira afrodescendente”, publicado em 2002, o reconhecimento da literatura afro-brasileira se dá no bojo da revisão que a historiografia literária brasileira tem empreendido nas últimas décadas e que implica, necessariamente, o abalo da noção de uma identidade nacional una e coesa (DUARTE, 2002, p. 47). Afinal, trata-se de contemplar também textos que expressam a sensibilidade e o imaginário dos afrodescendentes, marcados por uma experiência histórica, social e cultural bastante singular. Experiência essa que põe em xeque o mito da democracia racial, defendido por Gilberto Freyre, e desmascara seus mecanismos mais ou menos sutis de discriminação.

No caso da obra de Lima Barreto, na qual, como bem lembra Schwarcz, "a ascensão social é tratada não só como aspiração, mas, sobretudo, como uma impossibilidade"(SCHWARCZ, 2010, p. 25), sua inserção nessa série literária específica põe em relevo os entraves vividos pela população afrodescendente, indiscutivelmente mais sensível às injustiças sociais.

O caso de Lima Barreto é emblemático da complexidade que envolve a condição dos autores negros e a qualificação de sua produção em nosso país. $\mathrm{O}$ tema da literatura afro-brasileira é delicado justamente por não haver ainda definições cabais acerca de tal produção. Se, por um lado, é simples reconhecer as literaturas africanas pelos espaços geográficos a que pertencem seus autores, por outro, torna-se difícil a definição da produção afro-brasileira apenas pelo aspecto da origem étnica de seus escritores. Sendo, portanto, um conceito ainda por ser constituído, como sugere o próprio título de outro artigo do pesquisador Eduardo de Assis Duarte, "Literatura afro-brasileira: um conceito em construção" (DUARTE, 2008), podem ser incluídas em seu espectro obras capazes de abranger alguns elementos constitutivos para a sua delimitação. Para tal autor: "A partir [...] da conjunção desses cinco grandes fatores - temática, autoria, ponto de vista, linguagem 
Linha D'Água (Online), São Paulo, v. 29, n. 1, p. 29-43, jun. 2016

e público - pode-se constatar a existência da literatura afro-brasileira em sua plenitude" (DUARTE, op. cit., p. 21).

Diante dessa perspectiva, pode-se definir, por exemplo, em que campo se situariam alguns dos textos de Castro Alves, que evidenciam a barbárie da escravidão. Segundo os critérios de Duarte, a obra do chamado "poeta dos escravos" não se enquadraria sob a designação afro-brasileira, posto que não atende aos quesitos de autoria e ponto de vista ligados à afrodescendência, ainda que sua temática esteja legitimamente inscrita na denúncia à servidão escravista existente em sua época (DUARTE, op. cit., p. 14).

Em posição diferente, encontra-se Lima Barreto, conforme já vimos, e também Machado de Assis, um escritor afro-brasileiro muitas vezes criticado por não adotar explicitamente o ponto de vista dos excluídos. A esse respeito, Duarte pondera:

Já Machado de Assis que, como funcionário do governo imperial, ostenta uma postura irrepreensível ao propiciar a libertação de inúmeros cativos, adota em seus textos um ponto de vista coerente com seu procedimento de cidadão. $\mathrm{E}$ a acusação de omisso que muitos tentaram the impingir cai por terra diante das centenas de matérias abolicionistas publicadas pela Gazeta de Notícias, órgão do qual era um dos sócios. E mais: em suas crônicas, sempre que aborda o cativeiro, acrescenta elementos judicativos, que ora lamentam a condição dos escravos, ora louvam a filantropia dos que os libertam, ora criticam os que apoiam ou se beneficiam do sistema [...] (DUARTE, op. cit., p. 16).

Se adotada a perspectiva de Duarte, parece realmente difusa a maneira pela qual a escola e a academia têm se aproximado da literatura afro-brasileira - sem uma delimitação precisa, sem se ancorar em premissas adequadas para sua compreensão. É interessante notar que, se nos ativermos apenas à presença de autores de origem negra nos currículos, é possível considerar que a academia e a própria escola já cumprem, em certa medida, a função de trabalhar com a literatura afro -brasileira, uma vez que alguns dos escritores do nosso cânone são afrodescendentes. Entretanto, é fundamental perceber que essa produção não é, ideológica e esteticamente, percebida como afro-brasileira, o que implica a não valorização da cultura negra nesses meios.

Vale frisar que defendemos a abordagem, nas aulas de português, de textos com qualidade literária, que promovam acréscimos à formação social e pessoal dos estudantes, contribuindo dessa maneira para um duplo projeto, que se relaciona, por um lado, com a formação intelectual e humana dos alunos e, por outro, com o questionamento do modelo eurocêntrico de desvalorização histórica do africano e 
Linha D'Água (Online), São Paulo, v. 29, n. 1, p. 29-43, jun. 2016

do afro-brasileiro, propondo em seu lugar a compreensão de nossa formação cultural híbrida, pautada pela diversidade.

Afinal, apenas incluir a temática na educação, sem a devida seleção de conteúdos, obras, autores e, principalmente, formas de abordagem, pode causar efeito contrário ao desejado, desvalorizando a história e a cultura africana e afro-brasileira. Assim, é importante que haja qualidade no que se propõe para estudo, porque somente a adequação ao tema não garante o que prevê a Lei 10.639/03, cujo objetivo é de valorização das culturas africanas e afro-brasileira.

Cumpre a professores/as de língua portuguesa, portanto, um posicionamento claro em suas aulas de literatura. Por mais que o cânone afro-brasileiro ainda esteja em construção, é importante que docentes que têm como objeto de trabalho a literatura nacional trabalhem textos literários, de reconhecido valor estético, que discutam a temática étnico-racial; e que reconheçam que há autores afrodescendentes que já participam - ou poderiam participar - do cânone de nossa literatura.

Tal discussão nem sempre é simples, mas deve ser incluída na abordagem das literaturas africanas e afro-brasileira, que devem se presentificar na escola não somente pela obrigatoriedade da Lei 10.639/03, senão pelo valor - estético e humano - que tais textos carregam, podendo contribuir para o desenvolvimento de práticas educativas mais relevantes e adequadas ao perfil do estudante brasileiro, especialmente para os de origem menos privilegiada, portadores da herança de pessoas que construíram nossa nação com muito trabalho e pouca (ou nenhuma) valorização.

Nesse sentido, o ensino de literatura se alia à formação pessoal de cada discente, da mesma maneira que pode ter um papel de denúncia frente às injustiças que se operam no cotidiano e, mais especificamente, no dia a dia da escola, cujo percurso histórico está calcado em exclusões sociais e étnico-raciais. Por isso, o ensino de história e cultura africana e afro-brasileira - campo em que se inserem suas literaturas - é de suma importância para o atual cenário educacional brasileiro. Se a escola pretende seguir rumo a uma educação mais democrática e igualitária, é preciso que resgate, construa e preserve, urgentemente, uma memória da África e dos afrodescendentes.

\section{Considerações finais}

Como vimos, a abordagem de textos literários pela escola brasileira apresentou desdobramentos diversos ao longo do tempo. Num passado relativamente recente, as obras literárias eram utilizadas para o ensino gramatical, servindo para a reprodução de regras linguísticas. Com o avanço da linguística aplicada à educação, houve um redirecionamento significativo, ampliando-se os gêneros textuais 
Linha D'Água (Online), São Paulo, v. 29, n. 1, p. 29-43, jun. 2016

utilizados no ensino e retirando, com isso, parte da primazia que o texto literário possuía nas aulas de português.

Em nossa perspectiva, a reorientação processada não deve diminuir de modo algum a presença da literatura em sala de aula, tampouco a importância do ensino de literatura. Ocorre, porém, que se tornaram necessárias novas reflexões sobre as funções do texto literário em ambiente escolar, uma vez que o estudo de suas estruturas e modelos de escrita considerados corretos e sua abordagem de caráter historicista e mecânico não fazem mais sentido na atualidade. Trata-se agora de se considerar o caráter emancipador da literatura, através da humanização possível dos sujeitos leitores e da construção de um ambiente de diálogo propício para se repensar o modo como a sociedade brasileira se desenvolveu histórica e socialmente.

De igual modo, não se pode desprezar o fato de que as literaturas africanas e afro-brasileira são de inestimável valor para o entendimento de nossas bases sociais e culturais. Por esse motivo, para além da obrigatória observação de preceitos legais que preveem a abordagem dessas literaturas durante a escolarização, é necessário atentar para as dimensões éticas e estéticas de tais textos, motivos mais do que suficientes para que façam parte do cotidiano da educação brasileira.

\section{Referências}

BARRETO, Lima. Contos completos. Organização e introdução de Lilia Moritz Schwarz. São Paulo: Companhia das Letras, 2010.

BRASIL. Diretrizes Curriculares Nacionais para a Educação das Relações Étnico-Raciais e para o Ensino de História e Cultura Afro-Brasileira e Africana. Distrito Federal: Conselho Nacional de Educação/Conselho Pleno, 2004.

. Orientaçôes e Açôes para a Educação das Relações Étnico-raciais. Brasília: SECAD, 2006.

. Parâmetros curriculares nacionais: língua portuguesa. Secretaria de Educação Fundamental. Brasília, 1997.

CANDIDO, Antonio. O direito à literatura. In: Vários escritos. Rio de Janeiro: Ouro sobre Azul, 2013.

COELHO, Nelly Novaes. Literatura infantil: teoria, análise, didática. São Paulo: Moderna, 2000. 
Linha D'Água (Online), São Paulo, v. 29, n. 1, p. 29-43, jun. 2016

DUARTE, Eduardo de Assis. Literatura afro-brasileira: um conceito em construção. In: Estudos de Literatura Brasileira Contemporânea, n. 31. Brasília, jan.-jun. de 2008, p. 11-23. Disponível em: http://periodicos.unb.br/index.php/estudos/article/view/2017/1590. Acesso em 26/01/2015.

. "Notas sobre a literatura brasileira afrodescendente". In: Poéticas da diversidade. Organização de Marli Fantini Scarpelli e Eduardo de Assis Duarte. Belo Horizonte: UFMG/FALE, 2002.

FREIRE, Paulo. Pedagogia da autonomia: saberes necessários à prática educativa. Rio de Janeiro: Paz e Terra, 2014.

GERALDI, João Wanderley. (org.). O texto na sala de aula. São Paulo: Anglo, 2012. . Portos de Passagem. São Paulo: Martins Fontes, 1997.

MARCUSCHI, Luiz Antônio. Produção textual, análise de gêneros e compreensão. São Paulo: Parábola Editorial, 2008.

MARTIN, Vima Lia. "Contos completos de Lima Barreto: sensibilidade e rebeldia”. In: Revista Via Atlântica. São Paulo, 2010, n. 18, p. 203-207.

ROCHA, Rosa Margarida de Carvalho. "Racismo e exclusão educacional: 'fingir não ver, não é o mesmo que não existir - é hora de passar adiante”. In: LAIA, Maria Aparecida de; SILVEIRA, Maria Lucia da; SZMYHIEL, Adriana. (orgs.). A Universidade e a formação para o Ensino de História e Cultura Africana e Indígena: Desafios e Reflexões. Cadernos CONE, São Paulo, 2011, p. 19-47.

SILVÉRIO, Valter Roberto et alli. Educação como prática da diferença. Campinas: Armazém do Ipê, 2006.

SOUZA, Renata Junqueira de; COSSON, Rildo. Letramento Literário: uma proposta para a sala de aula. Universidade Estadual Paulista (Unesp)/Univesp: s/d. Disponível em: http://www.acervodigital.unesp.br/bitstream/123456789/40143/1/01d16t08.pdf. Acesso em 23/01/2015.

ZILBERMAN, Regina. "O papel da literatura na escola”. In: Revista Via Atlântica. São Paulo, 2008, n. 14, p. 11-22.

Recebido em 16/03/2016

Aprovado em 24/05/2016

MARTIN, V. L. R.; BUENO, A. G. Por uma memória da África e dos afrodescendentes: 